\title{
EFICIÊNCIA DA FARINHA DESENGORDURADA DE GERGELIM COMO COMPLEMENTO PROTÉICO DA FARINHA EXTRUDADA DE CAUPI ${ }^{1}$
}

\author{
GERALDO ARRAES MAIA², YANINA MADALENA DE ARRUDA CALVETE³, FRANCISCO JOSÉ SIQUEIRA TELLES ${ }^{4}$,
} JOSÉ CARLOS SABINO MONTEIRO5 ${ }^{5}$ MIRANICE GONZAGA SALES 6

\begin{abstract}
RESUMO - O objetivo deste trabalho foi promover uma avaliação nutricional da mistura protéica desengordurada, obtida do gergelim (Sesamum indicum L.), com a farinha extrudada do caupi (Vigna unguiculata $\mathrm{L}$. Walp), utilizando-se métodos físicos, bioquímicos, nutricionais e sensoriais. Usando-se semente integral do gergelim, com $54,08 \%$ de óleo e $21,83 \%$ de proteína, obteve-se a semente descascada com baixa concentração de oxalatos, que foi usada para a produção de farinha desengordurada de gergelim (FDG) contendo 2,81\% de óleo e 59,16\% de proteína. A principal característica desta farinha foi sua alta concentração de aminoácidos sulfurados (30,88 mg/g proteína). Esta FDG foi usada como complemento da proteína da farinha do caupi obtida pelo processo de cozimento por extrusão (FEC), o que ocasionou a inativação de grande parte dos inibidores de tripsina. A proteína da farinha FEC mostrou uma concentração de $24,29 \%$, um baixo conteúdo de aminoácidos sulfurados $(17,22 \mathrm{mg} / \mathrm{g}$ proteína) e alto teor de lisina $(58,47 \mathrm{mg} / \mathrm{g}$ proteína). O alimento formulado foi considerado de boa qualidade nutricional.
\end{abstract}

Termos para indexação: Sesamum indicum, Vigna unguiculata, oxalatos, aminoácidos sulfurados, tripsina.

\section{EFFICIENCY OF DEFATTED SESAME FLOUR AS A PROTEIC SUPPLEMENT OF EXTRUDED COWPEA FLOUR}

\begin{abstract}
The purpuse of this work was to evaluate the nutritional and organoleptic efficiency of the defatted proteic mixture obtained from gergelim, with extruded flour from cowpea beans, using physical, biochemical, nutritional and sensory methods. Using integral sesame seed, with $54.08 \%$ of oil and $21.83 \%$ of protein, the dehusked seed with low concentration of oxalates, that was used in the production of defatted sesame flour (FDG) with $2.81 \%$ of oil and $59.16 \%$ of protein was obtained. The main characteristic of the flour was the high concentration of sulphur amino acids ( $30.88 \mathrm{mg} / \mathrm{g}$ protein). The FDG was used as a complement of the protein of the cowpea flour obtained through a extrusion cooking process (FEC) which inactivated the major part of the trypsin inhibitors. The protein of the flour (FEC) presented a concentration of $24.29 \%$, a low content of sulfur amino acids $(17.22 \mathrm{mg} / \mathrm{g}$ protein) and a high lysin content $(58.47 \mathrm{mg} / \mathrm{g}$ protein). The formulated food was considered of good nutritional quality.
\end{abstract}

Index terms: Sesamum indicum, Vigna unguiculata, oxalates, sulphur amino acids, trypsin.

\footnotetext{
${ }^{1}$ Aceito para publicação em 2 de dezembro de 1998.

${ }^{2}$ Eng. Agr., Ph.D., Dep. de Tecnol. de Alimentos, Centro de Ciências Agrárias, UFC, Caixa Postal 12.168, CEP 60356-000 Fortaleza, CE. E-mail: frutos@ufc.br

${ }^{3}$ Farm. Ind., M.Sc., UFC.

${ }^{4}$ Farm., Ph.D., UFC.

${ }^{5}$ Eng. Quím., M.Sc., UFC.

${ }^{6}$ Econ. Doméstica, Ph.D., Dep. de Econ. Doméstica, UFC.
}

\section{INTRODUÇÃO}

Nos países em desenvolvimento, a avaliação das dietas limitadas em proteínas é complicada pelas condições ambientais e sociais (doenças parasitárias e infecciosas) que tendem a aumentar as necessidades energético-protéicas.

A combinação de gergelim (Sesamum indicum $\mathrm{L}$.) com caupi (Vigna unguiculata L. Walp) é um exem- 
plo de alimentos não-convencionais que podem contribuir para atender às necessidades de proteína e energia de grupos humanos. O resíduo do gergelim, obtido a partir da extração de óleo, contém, em média, $50 \%$ de proteínas, ricas em aminoácidos sulfurados. O caupi, com uma média de $25 \%$ de proteína, possui um perfil de aminoácidos típico das leguminosas, ricas em lisina e baixas concentrações de aminoácidos sulfurados.

O objetivo do trabalho foi o de promover uma avaliação nutricional da mistura protéica desengordurada obtida do gergelim, com a farinha extrudada do feijão caupi, utilizando-se métodos físicos, bioquímicos, nutricionais e sensoriais.

\section{MATERIAL E MÉTODOS}

O gergelim usado foi proveniente da Cooperativa Central dos Produtores de Algodão Ltda (COCENTRAL), em Fortaleza, Ceará.

Um saco contendo $60 \mathrm{~kg}$ de feijão caupi, cultivar BR 1-Poty, foi obtido da Empresa de Pesquisa Agropecuária do Ceará (EPACE), proveniente do campo experimental de Crateús. Os grãos eram de cor morromavermelhado, com tonalidades variáveis, e mediam de 5 a $7 \mathrm{~mm}$ (largura) e 6 a $8 \mathrm{~mm}$ (comprimento).

A farinha desengordurada de gergelim (FDG) foi obtida da seguinte maneira: os grãos foram descascados, pela técnica de maceração em álcali, sendo em seguida secados em estufa de ar, triturados, e extraído o óleo através de um equipamento do tipo Soxhlet. A torta desengordurada obtida na extração do óleo foi colocada em estufa de circulação forçada de ar à temperatura de $50-55^{\circ} \mathrm{C}$, por oito horas, para a dessolventização. $\mathrm{O}$ produto seco foi processado em moinho de disco. A farinha assim obtida foi colocada em sacos de plástico tipo Zippy e conservados em freezer até 24 horas antes do uso.

A farinha extrudada de caupi (FEC) foi obtida da seguinte maneira: procedeu-se à moagem dos grãos em moinho de discos, e posteriormente adicionou-se água até obter-se farinha de feijão com $23 \%$ de umidade. A farinha úmida foi então extrudada em uma extrusora com rosca simples, e posteriormente foi secada em estufa com circulação forçada de ar, e temperatura entre $50^{\circ} \mathrm{C}$ e $55^{\circ} \mathrm{C}$, durante 12 horas. $\mathrm{O}$ produto seco foi processado em moinho de disco e depois acondicionado em sacos de plástico tipo Zippy, e guardados em freezer doméstico até 24 horas antes do uso.
Para a avaliação das características e propriedades químicas, bioquímicas e sensoriais obtidas com o uso simultâneo da FDG e FEC, utilizou-se uma formulação bastante usada na dieta local: o "tutu de feijão". O produto final foi obtido adicionando-se farinha de mandioca, sal, óleo, condimento e água às misturas pré-formuladas das farinhas em estudo.

Os resultados obtidos nas análises individuais das farinhas de caupi e de gergelim foram utilizados para determinar as diferentes possibilidades de complementação entre suas proteínas. Obtiveram-se, assim, as misturas $\mathbf{M}_{1}$, $\mathrm{M}_{2}$ e $\mathrm{M}_{3}$, com diferentes percentuais de cada farinha.

As quantidades de cada farinha, usadas nas diferentes misturas, foram combinações de 52:48 $\left(\mathrm{M}_{1}\right) ; 65: 35\left(\mathrm{M}_{2}\right)$ e 82:18 $\left(\mathrm{M}_{3}\right)$ partes de proteína da FEC e da FDG, respectivamente.

As proporções das misturas das farinhas e dos ingredientes usados foram estabelecidas realizando-se testes empíricos com diferentes porções de cada um. A partir das características observadas, determinou-se a seguinte formulação: $490 \mathrm{~g}$ de $\mathrm{M}_{1}, \mathrm{M}_{2}$ ou $\mathrm{M}_{3}$; $200 \mathrm{~mL}$ de água; 84,9 $\mathrm{g}$ de farinha de mandioca; $24 \mathrm{~g}$ de sal; $32 \mathrm{~g}$ de óleo; $7 \mathrm{~g}$ de alho; $50 \mathrm{~g}$ de pimentão; $140 \mathrm{~g}$ de cebola e $14 \mathrm{~g}$ de coentro.

A partir dos produtos obtidos $\left(\mathrm{F}_{1}, \mathrm{~F}_{2}\right.$ e $\left.\mathrm{F}_{3}\right)$ foram realizados os testes necessários à avaliação dos alimentos formulados.

Para as análises químicas e bioquímicas dos alimentos formulados $F_{1}, F_{2}$ e $F_{3}$, foram separados, logo após o preparo, $600 \mathrm{~g}$ de cada amostra. O material foi congelado em bandejas de alumínio e cortado em cubos. Os cubos congelados de aproximadamente $150 \mathrm{~g}$ foram colocados em placas, e liofilizados a $-50^{\circ} \mathrm{C}$ e vácuo fixo de 0,10 Torr. O tempo médio necessário à secagem foi de 10 horas. As amostras obtidas foram acondicionadas em frascos de vidro com tampa, colocados em dessecador contendo sílica.

As determinações da umidade, extrato etéreo, proteína bruta e cinzas das farinhas e alimentos formulados foram feitas segundo American Oil Chemists Society (1974), Association of Official Analytical Chemists (1990). O teor de fibra foi realizado conforme técnica descrita por Van de Kamer \& Van Junkel (1952). A determinação de cálcio foi efetuada de acordo com o método descrito pela Association of Official Analytical Chemists (1980). As determinações de aminoácidos foram realizadas em analisador automático BECKMAN-CL, no Departamento de Planejamento Alimentar e Nutrição da Unicamp, segundo técnica recomendada por Spackman et al. (1958). A concentração de inibidores da tripsina foi determinada segundo o método caseinolítico descrito por Kunitz (1947). A presença de lectinas nas amostras foi determinada usandose a técnica descrita por Moreira (1975). 
Para a avaliação sensorial das misturas indicadas, foi proposta uma formulação básica de "tutu de feijão", com um mínimo de ingredientes e sem adição de qualquer produto animal. A farinha de mandioca foi usada para dar o sabor e a textura característica do produto.

A medida da aceitabilidade das três formulações $\left(\mathrm{F}_{1}, \mathrm{~F}_{2}\right.$ e $F_{3}$ ) foi realizada pelo teste da Escala Hedônica estruturada de nove pontos, usando blocos completos balanceados.

Para este teste foi formada uma equipe não-treinada com 30 provadores adultos, sem distinção de idade ou sexo, conforme indicações de Watts et al. (1988).

A avaliação dos dados obtidos na análise sensorial foi realizada pela análise de variância (ANOVA).

\section{RESULTADOS E DISCUSSÃO}

A composição química centesimal da farinha desengordurada de gergelim é mostrada na Tabela 1 , e os valores obtidos estão de acordo com os citados por Ramachandra et al. (1970), Meksongsee \& Swatditat (1974) e Silva \& Riveros (1979).

Para utilizar a farinha de gergelim como complemento protéico, foi necessário quantificar seus aminoácidos, cujos valores obtidos constam na Tabela 2. Esses valores são superiores aos citados por Krishnamurthy et al. (1960) e Boloorforooshan
\& Markarkis (1979). A metionina foi a única exceção, pois aparece com valores bastante inferiores.

Na pesquisa de fatores antinutricionais na semente de gergelim não foi possível detectar a presença de inibidores de tripsina pela técnica proposta. Segundo Caldwell (1958), esses fatores estão ausentes na semente de gergelim. Também foi obtido resultado negativo na pesquisa de lectinas.

Os dados referentes à composição química centesimal da farinha extrudada de caupi constam da Tabela 3. Comparando esses valores aos relacionados pelo IBGE (1977) e McWatters (1983), pode-se verificar a coerência de resultados.

TABELA 1. Composição química da farinha desengordurada de gergelim dessecado. (Média dos resultados das análises em triplicata; valores em gramas/100 gramas).

\begin{tabular}{lcc}
\hline Constituintes & Em base úmida & Em base seca \\
\hline Umidade & 7,21 & - \\
Extrato etéreo & 2,81 & 3,03 \\
Proteína bruta $(\mathrm{Nx6,25)}$ & 59,16 & 63,78 \\
Cinzas & 5,77 & 6,22 \\
Fibras & 4,21 & 4,54 \\
Carboidratos $^{1}$ & 20,70 & 22,28 \\
Cálcio $^{1}$ & 0,14 & 0,151 \\
\hline
\end{tabular}

$\frac{\text { Cálcio }}{{ }^{1} \text { Valor obtido por diferença. }}$

TABELA 2. Composição de aminoácidos das farinhas desengordurada de gergelim e extrudada de feijão caupi.

\begin{tabular}{|c|c|c|c|c|}
\hline \multirow[t]{2}{*}{ Aminoácidos } & \multicolumn{2}{|c|}{$\begin{array}{l}\text { Farinha desengordurada } \\
\text { de gergelim }^{1}\end{array}$} & \multicolumn{2}{|c|}{$\begin{array}{l}\text { Farinha extrudada } \\
\text { de caupi }\end{array}$} \\
\hline & $\mathrm{gaa}^{3} / 100 \mathrm{~g}$ farinha & gaa/16 g N & $\mathrm{gaa} / 100 \mathrm{~g}$ farinha & gaa/16 g N \\
\hline Ácido aspártico & 7,00 & 11,2 & 3,75 & 15,11 \\
\hline Treonina & 3,04 & 4,86 & 1,35 & 5,44 \\
\hline Serina & 3,45 & 5,52 & 1,58 & 6,37 \\
\hline Ácido glutâmico & 16,32 & 26,11 & 5,52 & 22,24 \\
\hline Prolina & 2,29 & 3,66 & 1,03 & 4,15 \\
\hline Glicina & 3,49 & 5,58 & 1,10 & 4,43 \\
\hline Alanina & 3,37 & 5,39 & 1,25 & 5,04 \\
\hline $1 / 2$ Cistina & 0,89 & 1,44 & 0,09 & 0,39 \\
\hline Valina & 3,03 & 4,45 & 1,26 & 5,08 \\
\hline Metionina & 1,04 & 1,66 & 0,33 & 1,33 \\
\hline Isoleucina & 2,68 & 4,23 & 1,19 & 4,79 \\
\hline Leucina & 4,23 & 6,85 & 1,93 & 7,78 \\
\hline Tirosina & 2,33 & 3,73 & 0,76 & 3,06 \\
\hline Fenilalanina & 2,93 & 4,69 & 1,40 & 5,64 \\
\hline Lisina & 1,63 & 2,61 & 1,41 & 5,68 \\
\hline Histidina & 1,54 & 2,46 & 0,70 & 2,82 \\
\hline Arginina & 7,46 & 11,94 & 1,64 & 6,61 \\
\hline
\end{tabular}

${ }^{1}$ Proteína bruta $=24,8 \%$ com recuperação final de aminoácidos $=107,98 \%$.

${ }^{2}$ Proteína bruta $=62,49 \%$ e recuperação final de aminoácidos $=108,99 \%$.

${ }^{3}$ Gramas de aminoácidos. 
Os valores referentes às concentrações de aminoácidos das farinhas são mostrados na Tabela 2. A maior parte dos resultados são superiores aos encontrados por Boulter et al. (1973) e Otoul (1974), sendo exceção somente a cistina, com valores significativamente inferiores.

Para avaliar o efeito da extrusão do caupi sobre os fatores antinutricionais, foram determinadas as medidas de inibidores de tripsina no grão cru e na farinha extrudada. $\mathrm{O}$ valor encontrado para o grão cru foi 2,13 UI (unidade de inibidores)/mg de amostra. Comparando-o aos valores citados na literatura, conclui-se que é bastante baixo. Segundo Elias et al. (1976), as concentrações de inibidores de tripsina são dependentes do tipo de semente, já que em 10 variedades distintas obtiveram valores entre 4,6 a

TABELA 3. Composição química centesimal da farinha extrudada de caupi (FEC). (Média dos resultados de análises em triplicata).

\begin{tabular}{lcc}
\hline Constituinte & Em base úmida & Em base seca \\
\hline Umidade & 4,88 & - \\
Extrato etéreo & 1,02 & 1,07 \\
Proteína bruta $(\mathrm{Nx6,25)}$ & 24,29 & 25,54 \\
Cinzas & 3,29 & 3,46 \\
Fibras & 5,25 & 5,50 \\
Carboidratos ${ }^{1}$ & 61,27 & 64,43 \\
Cálcio & 0,07 & 0,08 \\
\hline
\end{tabular}

${ }^{1}$ Valor obtido por diferença.
13,7 UI/mg. A concentração de $0,09 \mathrm{UI} / \mathrm{mg}$ obtida na análise da farinha extrudada de caupi indica que houve uma diminuição considerável deste fator, que pode estar relacionado ao efeito do calor.

Os valores encontrados na análise de lectinas do grão cru foram muito baixos e por isto não foi possível assegurar a precisão dos resultados.

A Tabela 4 mostra as concentrações de aminoácidos essenciais das farinhas de gergelim e de caupi, expressas em $\mathrm{mg} / \mathrm{g}$ de proteína.

O percentual de 59,27 mostra que a lisina é o único aminoácido limitante no gergelim. No caupi, o valor de $78,27 \%$ indica serem os sulfurados os limitantes. Os outros aminoácidos essenciais tiveram resultados superiores a $100 \%$.

Os excessos de lisina no caupi e de sulfurados no gergelim possibilitam a obtenção de uma mistura do tipo III na classificação de Bressani (Steinke et al., 1980). Os valores obtidos para as misturas $M_{1}, M_{2} \mathrm{e}$ $\mathrm{M}_{3}$ constam da Tabela 5 .

A quantidade protéica indicada pelos resultados do cálculo do escore químico é significativamente maior nas três misturas, do que em qualquer uma das farinhas isoladamente. Isto mostra que a deficiência de lisina no gergelim e a deficiência de aminoácidos sulfurados no caupi, são reduzidas pela combinação das duas proteínas.

A Tabela 6 mostra as quantidades de FEC e FDG utilizadas e o percentual correspondente a cada uma nas misturas.

TABELA 4. Concentrações de aminoácidos essenciais das farinhas desengordurada de gergelim (FDG) e extrudada de caupi (FEC) e valores de escore químico ${ }^{1}$.

\begin{tabular}{|c|c|c|c|c|c|}
\hline \multirow{2}{*}{$\begin{array}{l}\text { Aminoácidos } \\
\text { essenciais }\end{array}$} & \multicolumn{2}{|c|}{ Concentração $^{2}$} & \multirow{2}{*}{$\begin{array}{c}\text { Proteína } \\
\text { padrão } \\
\text { FAO }\end{array}$} & \multicolumn{2}{|c|}{ Escore químico $^{3}$} \\
\hline & $\begin{array}{c}\text { Proteína } \\
\text { FDG }\end{array}$ & $\begin{array}{c}\text { Proteína } \\
\text { FEC }\end{array}$ & & $\begin{array}{c}\text { Proteína } \\
\text { FDG }\end{array}$ & $\begin{array}{c}\text { Proteína } \\
\text { FEC }\end{array}$ \\
\hline Treonina & 48,65 & 54,43 & 28 & 173,75 & 194,39 \\
\hline Sulfurados ${ }^{4}$ & 30,88 & 17,22 & 22 & 140,36 & $78,27^{5}$ \\
\hline Valina & 48,49 & 50,81 & 25 & 193,96 & 203,24 \\
\hline Isoleucina & 42,89 & 47,98 & 28 & 153,18 & 171,36 \\
\hline Leucina & 68,49 & 77,82 & 44 & 155,66 & 176,86 \\
\hline Fenilalanina & 46,89 & 56,45 & 22 & 213,14 & 256,59 \\
\hline Lisina & 26,08 & 58,47 & 44 & $59,27^{6}$ & 132,89 \\
\hline Histidina & 24,64 & 28,22 & 19 & 129,68 & 148,53 \\
\hline Triptofano & - & - & 9 & - & - \\
\hline
\end{tabular}

${ }^{1}$ Usando a proteína padrão FAO (1985).

2 Valores em mg de aminoácidos em $1 \mathrm{~g}$ de proteína, calculados sobre valores da Tabela 2.

3 Valores percentuais calculados pela fórmula indicada em FAO (1985).

${ }^{4}$ Cistina + metionina.

5 Aminoácido limitante na proteína do caupi.

6 Aminoácido limitante na proteína do gergelim. 
Comparando as Tabelas 5 e 6, foi possível observar que variações de dez pontos percentuais nos valores do escore químico implicam variações bastante significativas nas proporções das farinhas.

A aparência final de cada uma das três formulações variou conforme as proporções de farinhas de gergelim e caupi usadas. Aumentando a proporção de FDG, o alimento formulado adquiriu consistência mais cremosa e a cor ficou mais clara.

A Tabela 7 mostra o resultado do cálculo de quantidade esperada de farinha em $100 \mathrm{~g}$ de "tutu" e o percentual de proteína a que corresponde. Observase que a proporção do somatório dos dois tipos de farinha é constante, mudando o percentual de proteína conforme varia a proporção de FDG e FEC.

Os resultados dos cálculos estatísticos utilizando ANOVA, foram obtidos segundo Watts et al. (1988) e constam da Tabela 8.

Existem poucos exemplos de avaliação sensorial de produtos que utilizem a farinha de gergelim. Segundo Dench et al. (1981), a farinha produzida a partir da semente de gergelim é diferente daquelas obtidas da maioria das oleaginosas, já que não apresenta sabores estranhos nem pigmentos que possam prejudicar seu uso na formulação de alimentos.

Devadas et al. $(1978,1979)$ testaram e aprovaram o uso de diferentes proporções de gergelim em três formulações diferentes. Todos avaliados nutricional e sensorialmente em crianças escolares.

Cruz \& Hedrick (1985) avaliaram o uso da farinha de gergelim como substituto econômico da carne em salames fermentados. Nos testes foi substituído 8 , 18 e $27 \%$ de carne pela farinha, e houve uma aceitabilidade total dos dois primeiros produtos.

A Tabela 9 mostra a composição química centesimal das três formulações de "tutu de feijão"

TABELA 5. Valores do escore químico em percentual de aminoácidos limitantes nas misturas das farinhas desengordurada de gergelim (FDG) e extrudada de caupi (FEC) propostas.

\begin{tabular}{lccc}
\hline Aminoácido & Mistura 1 & Mistura 2 & Mistura 3 \\
limitante & $52: 48^{1}$ & $65: 35^{1}$ & $82: 18^{1}$ \\
\hline Sulfurados & 108,07 & 100,00 & 89,45 \\
Lisina & 97,55 & 107,12 & 119,64 \\
\hline
\end{tabular}

após liofilização. Utilizando os valores em base seca extrapolados para os níveis de $66,5 \%$ de umidade encontrados na análise do "tutu de feijão" pronto para consumo, obteve-se a composição dos três produtos conforme mostra a Tabela 10. Esses resultados confirmam os valores calculados para as misturas mostradas na Tabela 7 .

$\mathrm{O}$ alimento formulado $\mathrm{F}_{1}$ tem a maior proporção de proteínas pois contém maior quantidade de fari-

TABELA 6. Quantidades das farinhas desengordurada de gergelim (FDG) e extrudada de caupi (FEC) usadas nas misturas.

\begin{tabular}{lrcc}
\hline Farinha & Percentual & Peso $(\mathrm{g})^{1}$ & Proteína $(\mathrm{g})^{1}$ \\
\hline Mistura 1(52:48) & & & \\
Caupi & 72,52 & 355,33 & 86,31 \\
Gergelim & 27,48 & 134,67 & 79,67 \\
Mistura 2 $(65: 35)^{2}$ & & & \\
Caupi & 81,90 & 401,29 & 97,47 \\
Gergelim & 18,10 & 88,71 & 52,48 \\
Mistura 3 (82:18) & & & \\
Caupi & 91,73 & 449,48 & 109,18 \\
Gergelim & 8,27 & 40,52 & 23,97 \\
\hline Em 490 g de mistura final. & &
\end{tabular}

2 Proporção FEC: FDG.

TABELA 7. Percentual de farinha desengordurada de gergelim e extrudada de caupi e proteína de "tutu de feijão" nas formulações $F_{1}, F_{2}$ e $F_{3}{ }^{1}$.

\begin{tabular}{lrrr}
\hline Ingredientes & $\mathrm{F}_{1}$ & $\mathrm{~F}_{2}$ & \multicolumn{1}{c}{$\mathrm{F}_{3}$} \\
\hline Gergelim & & & \\
Farinha (\%) & 7,09 & 4,68 & 2,13 \\
Proteína (\%) & 4,19 & 2,76 & 1,26 \\
Caupi & & & \\
Farinha (\%) & 18,70 & 21,11 & 23,66 \\
Proteína (\%) & 4,54 & 5,13 & 5,75 \\
Total & & & \\
Farinha (\%) & 25,79 & 25,79 & 25,79 \\
Proteína (\%) & 8,73 & 7,89 & 7,01 \\
\hline
\end{tabular}

${ }^{1}$ Valores calculados sobre as concentrações de aminoácidos obtidos nas análises das farinhas.

TABELA 8. Resultados estatísticos da análise de variância das notas obtidas na análise sensorial através de blocos complementares balanceados.

\begin{tabular}{lcccc}
\hline Fonte & Soma das áreas & DF & Área de significância & Razão F \\
\hline Tratamento & 356 & 2 & 0,178 & 0,066 \\
Provador & 115,156 & 29 & 3,971 & 1,467 \\
Resíduo & 156,978 & 58 & 2,707 & - \\
Total & 272,489 & 89 & - & - \\
\hline
\end{tabular}

Pesq. agropec. bras., Brasília, v.34, n.7, p.1295-1303, jul. 1999 
TABELA 9. Composição química centesimal de três formulações $\left(F_{1}, F_{2}\right.$ e $\left.F_{3}\right)$ de "tutu de feijão" após liofilização. (Média de resultados de análises em triplicata).

\begin{tabular}{|c|c|c|c|c|c|c|}
\hline \multirow[t]{2}{*}{ Constituinte } & \multicolumn{2}{|c|}{ Alimento $F_{1}$} & \multicolumn{2}{|c|}{ Alimento $F_{2}$} & \multicolumn{2}{|c|}{ Alimento $F_{3}$} \\
\hline & B. úmida & B. seca & B. úmida & B. seca & B. úmida & B. seca \\
\hline Umidade & 8,54 & - & 8,01 & - & 8,28 & - \\
\hline Extrato etéreo & 5,47 & 5,98 & 4,96 & 5,39 & 4,51 & 4,92 \\
\hline Proteína bruta ${ }^{1}$ & 24,28 & 26,55 & 21,20 & 23,05 & 19,08 & 20,80 \\
\hline Cinzas & 6,01 & 6,57 & 5,90 & 6,41 & 5,21 & 5,68 \\
\hline Fibras & 4,32 & 4,72 & 4,47 & 4,86 & 5,01 & 5,46 \\
\hline Carboidratos $^{2}$ & 51,38 & 56,18 & 55,46 & 60,29 & 57,91 & 63,14 \\
\hline
\end{tabular}

${ }^{1}$ Calculada usando Nx6,25.

2 Obtidos por diferença.

nha de gergelim por grama de farinha da mistura. Sabe-se que a concentração protéica na FDG (em base seca) é de $63,78 \%$ enquanto na FEC é de $25,54 \%$.

A concentração de inibidores de tripsina foi ainda menor que obtida na análise da farinha de feijão extrudada. Os valores dos alimentos formulados $\mathrm{F}_{1}$, $\mathrm{F}_{2}$ e $\mathrm{F}_{3}$ foram $0,033,0,036$ e $0,039 \mathrm{UI} / \mathrm{mg}$ de amostra, respectivamente.

Não foram realizadas as análises de lectinas, já que os resultados obtidos nas farinhas foram negativos.

A Tabela 11 mostra a composição em aminoácidos da proteína das formulações de "tutu de feijão". Comparando-se esses resultados aos perfis obtidos nas análises das farinhas de gergelim e caupi (Tabela 2), percebe-se que houve um aumento em relação à concentração dos aminoácidos limitantes de cada uma.

A Tabela 12 apresenta as concentrações dos aminoácidos essenciais em $\mathrm{mg} / \mathrm{g}$ de proteína, que foram usadas para o cálculo do escore químico. Os valores obtidos referentes aos aminoácidos limitantes das três formulações constam da Tabela 13. Segundo tais resultados, conclui-se que em qualquer um dos três formulados a concentração de sulfurados foi superior à da FEC, e a lisina, superior à da FDG. Isto significa aumento na qualidade protéica.

No caso das formulações $F_{1}$ e $F_{2}$, os valores de escore químico para os dois aminoácidos limitantes foram acima de 100, o que indica que as proteínas dos formulados satisfazem os padrões para escolares indicados pela FAO (1985).

Comparando-se os resultados dos três alimentos formulados, considerou-se que a melhor combinação foi a utilizada na formulação $\mathrm{F}_{2} \operatorname{com} 65: 35 \%$ de
TABELA 10. Composição química centesimal estimada da composição de três formulações de "tutu de feijão" $\left(F_{1}, F_{2}\right.$ e $\left.F_{3}\right)$ pronto para consumo.

\begin{tabular}{lccc}
\hline Constituinte & Alimento $\mathrm{F}_{1}$ & Alimento $\mathrm{F}_{2}$ & Alimento $\mathrm{F}_{3}$ \\
\hline Matéria seca & 33,5 & 33,5 & 33,5 \\
Umidade & 66,5 & 66,5 & 66,5 \\
Extrato etéreo & 2,00 & 1,81 & 1,65 \\
Proteína bruta & 8,89 & 7,72 & 6,97 \\
Cinzas & 2,20 & 2,15 & 1,90 \\
Fibra & 1,58 & 1,63 & 1,83 \\
Carboidratos & 18,83 & 20,19 & 21,15 \\
\hline${ }^{1}$ Obtidos por diferença. & & &
\end{tabular}

TABELA 11. Composição em aminoácidos de três formulações de "tutu de feijão" $\left(F_{1}, F_{2}\right.$ e $\left.F_{3}\right)$. (Valores em gramas de aminoácidos/16 g N) ${ }^{1}$.

\begin{tabular}{|c|c|c|c|}
\hline Aminoácidos & $\mathrm{F}_{1}$ & $\mathrm{~F}_{2}$ & $\mathrm{~F}_{3}$ \\
\hline Ácido aspártico & 9,88 & 11,30 & 11,42 \\
\hline Treonina & 3,935 & 4,152 & 4,159 \\
\hline Serina & 5,09 & 5,01 & 4,84 \\
\hline Ácido glutâmico & 20,78 & 18,77 & 19,42 \\
\hline Prolina & 4,36 & 4,554 & 3,748 \\
\hline Glicina & 4,91 & 5,48 & 4,67 \\
\hline Alanina & 4,88 & 4,57 & 4,48 \\
\hline $1 / 2$ Cistina & 0,802 & 0,699 & 0,660 \\
\hline Valina & 4,319 & 5,055 & 4,973 \\
\hline Metionina & 2,015 & 1,632 & 1,467 \\
\hline Isoleucina & 3,572 & 4,308 & 4,150 \\
\hline Leucina & 7,311 & 7,017 & 7,182 \\
\hline Tirosina & 3,38 & 2,95 & 3,05 \\
\hline Fenilalanina & 5,174 & 5,402 & 5,583 \\
\hline Lisina & 4,735 & 4,912 & 5,732 \\
\hline Histidina & 2,862 & 3,004 & 3,086 \\
\hline Arginina & 9,99 & 8,85 & 7,91 \\
\hline Proteínas totais ${ }^{2}$ & $25,24 \%$ & $21,99 \%$ & $19,67 \%$ \\
\hline
\end{tabular}

1 Valores extrapolados para $100 \%$ de recuperação.

2 Resultados obtidos em análise por micro-Kjeldahl. 
proteína de caupi:gergelim. Neste caso, os valores de escore químico foram $105,95 \%$ para sulfurados e $111,64 \%$ para lisina. Obteve-se boa margem de segurança para os dois aminoácidos, com menor quantidade de farinha de gergelim, do que a usada na formulação $\mathrm{F}_{1}$.

Nielsen et al. (1983) encontraram que a melhor mistura entre o gergelim e o feijão comum ocorreu quando as farinhas foram combinadas na proporção de 50:50.

Na combinação entre o feijão-fava (Vicia fava) e o gergelim, a melhor relação encontrada por Al-Nouri et al. (1980) foi aquela cujas proteínas foram misturadas na proporção de 50:50.

A farinha de gergelim aparece como tendo uma digestibilidade elevada para uma proteína vegetal. Para Nielsen et al. (1983) o valor da digestibilidade verdadeira do gergelim em relação à caseina é de $86,34 \%$. A farinha de caupi possui índice menor que o gergelim, sendo, porém, bem superior do feijãopreto e a outras leguminosas. Segundo Elias et al. (1976), o valor da digestibilidade da farinha extrudada de caupi é de 80,82\%. Esse índice é característico de farinhas extrudadas, sendo mais elevado do que os obtidos em outros tipos de cozimento.

Observa-se, na Tabela 14, que o uso de farinha de gergelim aumenta a digestibilidade do alimento formulado, elevando, assim, o seu valor nutricional.

TABELA 12. Composição em aminoácidos essenciais de três formulações de "tutu de feijão" $\left(F_{1}, F_{2}\right.$ e $\left.F_{3}\right)$, valores em miligramas de aminoácidos/g de proteína.

\begin{tabular}{llll}
\hline Aminoácidos & $\mathrm{F}_{1}$ & $\mathrm{~F}_{2}$ & $\mathrm{~F}_{3}$ \\
\hline Treonina & 39,35 & 41,52 & 41,59 \\
Sulfurados ${ }^{1}$ & 28,17 & 23,31 & 21,27 \\
Valina & 43,19 & 50,55 & 49,73 \\
Isoleucina & 35,72 & 43,08 & 41,50 \\
Leucina & 73,11 & 70,17 & 71,82 \\
Fenilalanina & 51,74 & 54,02 & 55,83 \\
Lisina & 47,35 & 49,12 & 57,32 \\
Histidina & 28,62 & 30,104 & 30,86 \\
Triptofano & - & - & - \\
\hline Aminoácidos sulfurados $=$ cistina + metionina.
\end{tabular}

TABELA 13. Cômputo químico, expresso em percentual, dos aminoácidos limitantes em três formulações de "tutu de feijão" $\left(F_{1}, F_{2} \text { e } F_{3}\right)^{1}$.

\begin{tabular}{lccc}
\hline Aminoácidos & Alimento $\mathrm{F}_{1}$ & Alimento $\mathrm{F}_{2}$ & Alimento $\mathrm{F}_{3}$ \\
\hline Sulfurados & 128,04 & 105,95 & 96,68 \\
Lisina & 107,61 & 111,64 & 130,27 \\
\hline
\end{tabular}

TABELA 14. Valores da digestibilidade da proteína de três formulações de "tutu de feijão"1.

\begin{tabular}{lccc}
\hline Formulações & $\begin{array}{c}\text { Fração do total } \\
\text { de proteína } \\
(\mathrm{X})\end{array}$ & $\begin{array}{c}\text { Digestibilidade } \\
(\mathrm{Y})\end{array}$ & $\begin{array}{c}\text { Digestibilidade } \\
\text { da proteína da } \\
\text { mistura }^{2}\end{array}$ \\
\hline Mistura 1 & & & 83,15 \\
Far. caupi & 0,52 & $80,20^{3}$ & \\
Far. gergelim & 0,48 & 86,34 & \\
Mistura 2 & & & 83,35 \\
Far. caupi & 0,65 & 80,20 & \\
Far. gergelim & 0,35 & 86,34 & \\
Mistura 3 & & & 81,30 \\
Far. caupi & 0,82 & 80,20 & \\
Far. gergelim & 0,18 & 86,34 & \\
\hline
\end{tabular}

${ }^{1}$ Segundo FAO (1985).

2 Digestibilidade da mistura $=(\mathrm{X} \times \mathrm{Y}$ caupi $)+(\mathrm{X} \times \mathrm{Y}$ gergelim $)$.

3 Segundo Nielsen et al. (1983), em percentual.

\section{CONCLUSÕES}

1. A moagem da torta desengordurada de gergelim produz uma farinha com ótima textura e cor bastante clara.

2. A farinha desengordurada de gergelim apresenta elevado valor protéico, e portanto com potencial para utilização em diversas formulações.

3. A proteína da farinha desengordurada de gergelim é rica em sulfurados; o aminoácido limitante é a lisina.

4. A proteína da farinha extrudada de caupi é rica em lisina e pobre em aminoácidos sulfurados.

5. Há um efeito complementar com significativo aumento na qualidade protéica das misturas de farinhas obtidas neste trabalho.

6. A utilização de misturas com farinha desengordurada de gergelim produzem um alimento de alto valor nutricional. 


\section{REFERÊNCIAS}

AL-NOURI, F.F.; SIDDIQI, A.M.; MARKARKIS, P. Protein supplementacion of broad beans with sesame. Food Chemistry, v.5, n.4, p.309-313, 1980.

AMERICAN OIL CHEMISTS SOCIETY. The official and tentative methods. 3.ed. Washington, DC, 1974. Não paginado.

ASSOCIATION OF OFFICIAL ANALYTICAL CHEMISTS. Official methods of analysis. 13.ed. Washington, DC, 1980. 1018p.

ASSOCIATION OF OFFICIAL ANALYTICAL CHEMISTS. Official methods of analysis. 15.ed. Washington, DC, 1990. 2v, 1213p.

BOLOORFOROOSHAN, M.; MARKARKIS, P. Protein supplementation of navy beans with sesame. Journal of Food Science, v.44, n.2, p.390-391, 1979

BOULTER, D.; EVANS, I.M.; THOMPSON, A.; YARWOOD, A. The aminoacid composition of V.u. meal in relation to nutrition. In: MILNER, M. (Ed.). Nutrition improvement of food legumes by breeding. NewYork: PAG - United Nation System, 1973. p.205-216.

CALDWELL, R.W. Sesame meal. In: ALTSCHUL, A.M. (Ed.). Processed protein foodstuffs. New York: Academic, 1958. p.535-556.

CRUZ, O.A.; HEDRICK, H.B. Utilization of defatted sesame flour in fermented salami. Journal of Food Science, v.50, p.1177-1178, 1985.

DENCH, J.E.; RIVAS, N.; CAYGILL, J.C. Selected functional properties of sesame (s.i.) flour and two protein isolates. Journal of the Science of Food and Agriculture, v.32, p.557-564, 1981.

DEVADAS, P.R.; KAMALANATHAN, G.; UPPUTHAI, V. Supplementary value of leaf protein, leaf protein and sesame meal and sesame meal and coconut meal in the diets of preschoolers. Indian Journal of Nutrition and Dietetics, v.15, p.175180,1978

DEVADAS, P.R.; KAMALANATHAN, G.; UPPUTHAI, V.; JAMALA, S.; AMUDHA SVRABHI, V. Evaluation of a food supplement to school children. Indian Journal of Nutrition and Dietetics, v.16, p.335-341, 1979.
ELIAS, L.G.; CRISTALES, F.R.; BRESSANI, R.; MIRANDA, H. Composición química y valor nutritivo de algunas leguminosas de grano. Turrialba, v.26, n.4, p.376-380, 1976.

FAO (Roma, Itália). Necessidades de energia y de proteínas. Ginebra: FAO/OMS/UNU, 1985. (Informes técnicos).

IBGE. (Rio de Janeiro, RJ). Estudo nacional de despesa familiar (ENDEF). Consumo alimentar: antropometria (Região V). Rio de Janeiro, 1977. 72p.

KRISHNAMURTHY, K.; TASKER, P.K.; RAMANKRISHNAM, R. Nutritive value of sesame seed. Annals Biochemists, v. 20, n.3, p.73-76, 1960.

KUNITZ, M. Crystalline soybean trypsin inhibitor. II. General properties. Journal of General Physiology, v.30, p.291-310, 1947.

McWATTERS, K.H. Composition, physical and sensory characteristics of Akara processed form cowpea paste and Nigerian cowpea flour. Cereal Chemists, v.60, n.5, p.333-336, 1983 .

MEKSONGSEE, L.A.; SWATDITAT, A. Preparation of de hulled, defatted sesame flour. Thai Journal of Agricultural Science, v.7, p.213-223, 1974.

MOREIRA, R.A. Isolamento e caracterização de uma lecitina de P.v. Rio de Janeiro: UFRJ, 1975. 111p. Tese de Doutorado.

NIELSEN, B.; HEVIA, P.; BRITO, O. Study on the complementation of two proteins of low quality: black bean (P.v.) and sesame (S.i.). Journal of Food Science, v.48, p.1804-1806, 1983.

OTOUL, E. Répartition des principaux acides aminés dans les différentes parties de la graine d'un cultivar de Vigna unguiculata, (L.) Walp. Bulletin des Recherches Agronomiques de Gembloux, v.9, n.3, p.243-253, 1974.

RAMACHANDRA, B.S.; SHAMANTHAKA SASTRY, M.C.; SUBBA RAO, L.S. Process development studies on the wet dehulling and processing of sesame seeds to obtain edible protein concentrates. Journal of Food Science and Technology, v.7, p.127-131, Sept. 1970

SILVA, G.S.; RIVEROS, H.S. Productos alimenticios derivados de ajonjoli. Revista del Instituto de Investigaciones de Tecnologicas, Bogotá, v.1, n.120, p.34-55, jul./ago. 1979. 
SPACKMAN, D.H.; STEIN, W.H.; MOORE, S. Automatic recording apparatus for use in the chromatography of amino acids. Analytical Chemistry, v.30, p.1190-1205, 1958.

STEINKE, F.H.; PRESCHER, E.E.; HOPKINS, D.T. Nutritional evaluation (PER) of isolated soybean protein and combinations of food proteins. Journal of Food Science, v.45, p.323-327, 1980.
VAN DE KAMER, J.H.; VAN JUNKEL, L. Rapid determination of the crude fiber in cereals. Cereal Chemistry, v.29, p.239-245, 1952.

WATTS, B.M.; YLIMAKI, G.L.; JEFFERY, L.E.; ELIAS, L.G. Basic sensory methods for food evaluation. Otawa: The International Development Research Centre, 1988. 145p. 